\title{
Mecanismos da difusão global do Orçamento Participativo: indução internacional, construção social e circulação de indivíduos*
}

Osmany Porto de Oliveira

\section{Introdução}

Quando em Davos na Suíça, no ano de 2001, ocorria o Fórum Econômico Mundial, evento criado em 1972, do outro lado do Atlântico surgia um contramovimento. Era uma expressão oposta, manifestação da sociedade civil internacional. Ao sul do Brasil acontecia o Primeiro Fórum Social Mundial (FSM). Os olhos do mundo se dividiram entre Davos e Porto Alegre. Esse foi um primeiro passo para a capital gaúcha entrar no mapamúndi. Ali se reuniram mais de 20 mil pessoas e Porto Alegre se consagrou como a "Meca" dos movimentos sociais. O ideal de que "um outro mundo era possível", com uma sociedade mais democrática, justa e inclusiva, parecia se tornar realidade. A experiência de participação social de Porto Alegre, o Orçamento Participativo (OP), mostrava que uma "utopia havia se tornado realidade".

O OP pode ser definido sinteticamente como uma política de participação social, cujo objetivo é incluir a população no processo de alocação orçamentária. No modelo desenvolvido na cidade de Porto Alegre, cerca de $10 \%$ do orçamento municipal era submetido ao OP, que ocorria em um ciclo anual. Durante esse período assembleias eram realizadas entre os bairros da cidade, das quais toda a população podia participar e votar em prioridades de obras a serem executadas pela prefeitura. Paralelamente, eram realizadas assembleias temáticas em setores como transporte, esporte, cultura, entre outros. Em seguida, representantes eleitos nos bairros, os "conselheiros do Orçamento Participativo", deliberavam acerca das demandas mais votadas em um fórum central, o Conselho do Orçamento Participativo (COP). Um conjunto de demandas de políticas públicas era selecionado pelo COP e passava então a ser analisado pela prefeitura. Uma vez verificada sua viabilidade, as políticas eram implementadas e os conselheiros podiam acompanhar e fiscalizar a execução das obras.

Argumento que um grupo de indivíduos que chamo de "embaixadores da participação" foi fundamental para inserir o OP na agenda das instituições internacionais. Estas últimas ampliaram o potencial de difusão do OP. A incorporação do OP nas instituições internacionais e sua difusão massiva têm um significado inédito. De fato,

\footnotetext{
* Este artigo foi produzido a partir dos resultados de minha pesquisa de doutorado, publicada em uma versão mais ampla e detalhada, ver Porto de Oliveira (2016).
} 
trata-se de um movimento global em que se reconhece a importância da participação da sociedade no processo de gestão das políticas públicas. Esse processo é permeado por dinâmicas de tradução dos elementos cognitivos imbuídos no OP. Para Latour as operações de tradução estão relacionadas aos interesses e às interpretações atribuídas, por distintos atores, a um determinado objeto (Latour, 2005, p. 260). Isso significa dizer que, no caso do OP, à medida que o dispositivo circula - de uma instituição para a outra, de um município ao outro e de um país ao outro - ocorrem apropriações que transformam seu conteúdo ideológico ou o projeto político que nele está contido. Grosso modo, o OP passa de um método idôneo para alcançar a radicalização da democracia, no FSM, a um instrumento de combate à corrupção, controle social e luta contra a pobreza, no Banco Mundial.

A estratégia da narrativa foi desenhada de modo a conservar a riqueza das informações construídas a partir das informações empíricas coletadas, sem perder o rigor da análise. Inicialmente é apresentada a literatura que considera a difusão do OP. Em seguida, é descrita brevemente a estratégia de pesquisa, e os mecanismos da difusão são introduzidos. Os mecanismos não são mencionados explicitamente na narrativa processual, mas apenas retomados na conclusão para fins de fluidez do texto e clareza do argumento. Duas seções são dedicadas à parte empírica. A apresentação do processo envolve o movimento do "ponto de virada" e a difusão massiva. A reconstrução do processo é feita a partir de quatro instituições internacionais. Na primeira seção, "Argumentos sobre a difusão do OP", considera-se o papel do FSM no processo de difusão do OP. Já a segunda seção, "Estratégia de pesquisa da difusão internacional", trata da ação de três organizações internacionais: a ONU, a União Europeia e o Banco Mundial.

\section{Argumentos sobre a difusão do OP}

Os argumentos sobre a difusão internacional do OP são genéricos e descritivos, além de não explorar as relações causais que produziram esse fenômeno. Isso se deve em grande parte ao fato de o tema ter sido incorporado na literatura de forma lenta, com estudos muito pontuais que aumentaram só recentemente, a despeito da ampla adoção dessa política de participação social desde 2000 e da vasta bibliografia existente sobre o OP.

Allegretti e Herzberg publicaram em 2004 um artigo pioneiro intitulado "El retorno de las carabelas", que tratava da dinâmica de aprendizagem mútua nos processos de cooperação internacional, a qual havia permitido que modelos alternativos de democracia e participação social desenvolvidos no Sul migrassem para os países europeus. Cabannes (2006) apresentou os caminhos percorridos pelo OP em diferentes países da América Latina, apontando os atores que haviam contribuído para a adoção do OP em cada país, identificando a ação de ONGs, movimentos sociais e partidos 
políticos. Mais específico foi um estudo de caso sobre a transferência do OP de Porto Alegre a Saint-Denis, na periferia de Paris (Porto de Oliveira, 2010). Nesse estudo foi defendido que o OP teria sido transferido da cidade brasileira à francesa por duas razões complementares: a aspiração do município de se projetar internacionalmente e a de criar um vínculo mais estreito com a população local.

O primeiro levantamento das experiências internacionais de OP foi lançado em $2010^{1}$ em uma publicação técnica da agência alemã "Service Agency Communities in One World", assinado por Sintomer, Herzberg e Allegretti (2013). A primeira versão do estudo divulgou entre 795 e 1.469 casos, que, na versão atualizada publicada em 2013, estimou 2.788 casos distribuídos nos diversos cantos do globo ${ }^{2}$. Esse foi um grande passo, pois ajudou a oferecer um plano global da difusão do OP e situar o pesquisador diante da variedade de adaptações existentes. Para esses autores o OP é uma espécie de ideoscape, isto é, "um modelo que viaja ao redor do mundo e que existe somente por meio de suas diferentes implementações locais, que contribuem continuamente para modificar o modelo em si" (Sintomer, Herzberg e Allegretti, 2013, p. 13).

Dois anos mais tarde, em dezembro de 2012, Brian Wampler coeditou um número de Journal of Public Deliberation com o título "The spread of participatory budgeting across the globe: adoption, adaptation, and impacts". Merecem destaque no dossiê o artigo de Benjamin Goldfrank e o de Ernesto Ganuza e Gianpaolo Baiocchi. Para Goldfrank (2012), se inicialmente o principal promotor do OP era o Partido dos Trabalhadores (PT), nos dias atuais é o Banco Mundial, o qual teria transformado a política em uma de suas prescrições globais (global script), ou seja, uma receita padronizada que se recomenda aos municípios. Goldfrank argumenta que há dois tipos de promotores do OP dentro do Banco Mundial, os que reconhecem o dispositivo como um instrumento capaz de promover a agenda neoliberal e aqueles que acreditam no seu potencial democratizador. O autor avançou na compreensão da difusão internacional, mas ainda não se sabe ao certo como são compostas essas tendências de atores, quem são eles ou elas e, tampouco, como o OP, de fato, entrou na agenda do Banco Mundial. Por seu turno, Ganuza e Baiocchi (2012) enfatizaram o poder da ambiguidade do OP como um elemento que facilitou sua difusão. Os autores insistem no fato de que a difusão do OP é permeada de traduções e que, para se difundir, seu significado foi transformado. Com efeito, ao circular, o OP tornou-se maleável e passou a absorver diferentes conteúdos, e a mesma política que foi originada em Porto Alegre, defendendo a ideia da radicalização da democracia, não é a mesma que é promovida pelo Banco Mundial.

\footnotetext{
${ }^{1}$ A versão em português foi publicada em 2012.

${ }^{2}$ Não se sabe com precisão quais critérios os autores utilizam para considerar no universo dos OPs no mundo aquelas experiências que aparecem no levantamento. A definição é restritiva e normativa, uma vez que leva em conta somente experiências consideradas pelos autores como "genuínas" de OP. Ainda que confusa, trata-se do melhor levantamento disponível até o momento.
} 
A despeito do acúmulo de trabalhos publicados, que teve a vantagem de deslanchar o tema da difusão nesse campo de pesquisa, não há ainda coordenação entre a produção, nem um diálogo mais aderente à literatura específica da área, a saber, a difusão de políticas públicas. Ainda não há um argumento preciso sobre as causas da difusão do OP, de suas microdinâmicas ou do processo como um todo. Vale notar que a literatura foi surgindo e ganhando corpo durante o período em que a presente pesquisa estava sendo desenvolvida, isto é, entre 2008 e 2014. Além disso, os estudos sobre a difusão do OP fazem parte da literatura internacional. No Brasil, a publicação mais conhecida é a de Brian Wampler (2008), na revista Opinião Pública, sobre seu estudo a respeito da difusão do OP no âmbito nacional. Nesse contexto, analisar a difusão do OP no início desta pesquisa significou ingressar num campo de informações muito precárias e ainda sem perspectiva de desenvolvimento. Esse processo é sintetizado na próxima seção.

\section{Estratégia de pesquisa da difusão internacional}

Como pesquisar a difusão internacional de uma política pública? Essa é uma pergunta fundamental para entender o Brasil contemporâneo, uma vez que este se tornou um "exportador de políticas" com programas como o Bolsa Família, o Programa Nacional de Alimentação Escolar e o Minha Casa, Minha Vida (Porto de Oliveira, 2016). Mais especificamente, como pesquisar a difusão global do OP? A estratégia de pesquisa adotada foi plural, estruturada a partir de métodos qualitativos. Por um lado, a pesquisa analítica foi desenvolvida a partir das técnicas de análise do processo (George e Bennett, 2005), que consistiu em identificar as cadeias causais que conduziram à difusão internacional. Por outro, a parte empírica foi realizada a partir da "etnografia política transnacional", uma estratégia própria que desenvolvi a partir da imersão direta e experiência com pesquisa de campo e da composição dos trabalhos presentes na literatura sobre a comparação transnacional das políticas públicas (Hassenteufel, 2005, a etnografia política (Schatz, 2009) e a investigação de campo multissituada (Marcus, 1995).

De acordo com Hassenteufel, para entender as políticas públicas contemporâneas é preciso fazer comparações transnacionais, que considerem a difusão internacional. Isso significa que é fundamental analisar também os operadores das transferências, "estudar os lugares e espaços de interação (fóruns, colóquios, seminários, reuniões etc.) no seio dos quais os atores transnacionais vão difundir seus conceitos, estando em contato com outros atores nacionais" (Hassenteufel, 2005, p. 128, tradução nossa, assim como todas as demais traduções do artigo). Além disso, a pesquisa se baseou no conceito de etnografia "multissituada" de George Marcus (1995), que insiste na importância de estudar fenômenos que não ocorrem em um lugar específico, mas que se desdobram em diferentes sítios. Em síntese, trata-se de acompanhar os objetos que se difundem como 
estratégia de pesquisa, de modo a poder rastrear seu percurso. Marcus defende que é preciso seguir as pessoas envolvidas no fenômeno, os objetos em circulação, os símbolos e metáforas, a trama, a biografia dos atores e o conflito.

O desenho da pesquisa para entender o processo de difusão internacional do OP foi elaborado a partir de uma pesquisa empírica. O campo foi acessado por meio de diversas missões de pesquisa in loco ocorridas desde 2007 em nove países (África do Sul, Brasil, Equador, Espanha, Estados Unidos, França, Moçambique, Peru e Senegal). Foi acumulado denso material a partir de fontes primárias, o que ainda era inédito no campo de pesquisa. As missões de campo serviram para recolher três tipos de informações, que compõem a principal fonte utilizada para essa pesquisa. Foram realizadas mais de 125 entrevistas em profundidade, de duração média de uma hora. Em campo, foram coletados documentos oficiais, artigos de imprensa e materiais diversos (como panfletos, folders, informativos etc.). A observação participante foi realizada em plenárias e assembleias pontuais do OP, bem como em reuniões das Organizações da Sociedade Civil, por um lado, e em diversos eventos internacionais (Observatório Internacional da Democracia Participativa, 2008; Fórum das Autoridades Locais, 2009; Fórum Social Mundial, 2009, 2012; Metrópolis, 2012; Africités, 2012; II Encontro Anual sobre o Orçamento Participativo nos Estados Unidos, 2013). A literatura secundária constituiu uma fonte complementar, mas não prioritária para a elaboração do estudo.

É certo que um dos limites dessa natureza de análise é que a intensidade das informações e do campo varia, mas são compensadas pelas vantagens apresentadas acima. Os benefícios dessa estratégia é que traz dados inéditos, acessados a partir da observação nos bastidores da política ou da "globalização das políticas públicas", por meio da incursão em campos transnacionais e da realização de entrevistas. A importância de trazer essa natureza de informações a respeito da difusão de políticas brasileiras não é meramente descritiva, mas serve para entender as dinâmicas da difusão das políticas públicas, seus atores e os mecanismos que facilitam ou constrangem esse processo.

\section{Os mecanismos da difusão de políticas públicas}

O campo sobre a difusão de políticas é complexo e disputado por diversos autores, que reivindicam abordagens, categorias e métodos próprios. Há muitos termos para tratar da difusão de políticas, como lesson-drawing, transferência, difusão, mimetismo institucional, isomorfismo, entre outros que estão presentes na literatura. A profusão terminológica também se estende aos mecanismos usados para explicar o fenômeno, que são aproximadamente 104 de acordo com Graham, Shipan e Volden (2013, p. 690). Não é o propósito deste artigo entrar nos detalhes sobre a literatura da difusão de políticas, mas é preciso apresentar o conceito e os mecanismos usados neste estudo para explicar o processo de difusão do OP. 
A difusão internacional de políticas públicas, para Simmons, Dobbin e Garrett (2008, p. 7) "ocorre quando decisões políticas de um governo em um determinado país são sistematicamente condicionadas por escolhas previamente realizadas em outros países (por vezes mediadas pelo comportamento de organizações internacionais ou atores privados e organizações)". Já a transferência de políticas públicas, para Dolowitz e Marsh (2000, p. 5), consiste no "processo por meio do qual o conhecimento sobre políticas públicas, arranjos administrativos, instituições e ideias em um sistema político (no passado ou no presente) é usado para desenvolver políticas públicas, arranjos administrativos, instituições e ideias em outro sistema político". Em síntese a difusão pode ser entendida como "um processo, mediado ou não, a partir do qual um elemento, ou um conjunto de elementos, de ordem política (...) situado em algum lugar, no tempo ou no espaço, passe a ser adotado alhures" (Porto de Oliveira, 2016, p. 60).

As explicações para a difusão de políticas na literatura são múltiplas. Todavia, é possível identificar a partir da literatura um conjunto de mecanismos que facilitam esse processo e que são importantes para entender a difusão internacional do OP. Os mecanismos servem para explicar as microdinâmicas do processo de difusão. A partir da literatura e da observação empírica foram construídos três grandes tipos de mecanismos, que podem ser divididos nas seguintes categorias: institucional, social e individual.

O primeiro tipo de mecanismo da difusão consiste nas formas de indução institucional. Dolowitz e Marsh (2000, p. 8) colocam a adoção de uma política pública em um eixo contínuo, que tem na extremidade esquerda um componente voluntário e, na direita, um coercitivo. Trata-se do fato de uma instituição querer adotar uma política pública, porque aprendeu com outra instituição, tendo dessa forma racionalidade perfeita, ou então dever adotar uma política pública por imposição de outrem. As organizações internacionais podem influenciar de forma explícita ou implícita a adoção de políticas públicas, assim como promover transferências voluntárias ou coercitivas (Simmons, Dobbin e Garrett, 2008; Dolowitz e Marsh, 2000). A título ilustrativo é possível aludir ao papel do Fundo Monetário Internacional nas reformas estruturais do Estado na América latina nas décadas de 1980 e 1990 (Weyland, 2006). Por seu turno, a literatura sobre as relações federativas utiliza a noção de difusão de cima para baixo ou de baixo para cima, transferência em escala ou ainda transferência condicionada, que significa uma forma de difusão vertical do Estado para seus diversos entes e instituições (Porto de Oliveira, 2016). A ideia de condição também está presente nos estudos sobre o processo de integração institucional na União Europeia e se refere a adoção e harmonização das normas comunitárias da parte dos países membros (Saurugger e Surel, 2006, p. 195).

O segundo mecanismo está presente sobretudo nas abordagens sociológicas sobre o processo de construção social (Strang e Meyer, 1993; Simmons, Dobbin e Garrett, 2008, p. 31; Strang e Soule, 1998). Três argumentos presentes na literatura foram importantes para elaborar essa categoria. O primeiro é o fato de que a produção 
de teorias, paradigmas e teses, em geral, pode ser um mecanismo da difusão, no sentido de que estes postulam relações de causa e efeito (Strang e Meyer, 1993, p. 498; Hall, 1993). Um exemplo são os argumentos normativos encontrados na literatura técnica e acadêmica, como, por exemplo, o fato de o OP promover a justiça social, combater a corrupção, etc. O segundo argumento consiste na ideia de prestígio que uma prática acumula e que influencia a adoção por outros atores (Strang e Soule, 1998, p. 274-275). Há um pressuposto sociológico de que experiências com elevado grau de aceitação em uma comunidade tendem a ser replicadas em outros lugares. O pertencimento a um grupo cultural também incentiva a adoção, no sentido de que nas "comunidades políticas" há muitas vezes uma crença a respeito de qual é a forma mais "apropriada" para alcançar um resultado (Hall, 1993, p. 279; Simmons, Dobbin e Garrett, 2008, p. 32). A proximidade cultural, também, pode promover a difusão, como a identificação com categorias do tipo: países do Sul, América Latina, países de língua portuguesa etc.

O terceiro mecanismo é o da circulação internacional de indivíduos entre instituições que promoveram o OP. A sociologia das elites, especialmente em sua vertente francesa, tem enfatizado a importância dos indivíduos que se deslocam de um lugar ao outro ou de uma instituição para outra no processo de difusão. Dezalay e Garth (2002), em La mondialisation des guerres de palais, insistem na circulação das elites como um dos elementos que influenciam as reformas estruturais do Estado na América Latina. Para fins analíticos a circulação institucional é definida como um processo por meio do qual indivíduos estabelecidos em uma determinada instituição transitam para outras instituições facilitando a difusão. Esse mecanismo opera de forma recorrente no processo de difusão do OP. Com efeito, em várias etapas os "embaixadores da participação", ao migrarem do município para o estado, de instituições nacionais para internacionais, de ONGs para a academia, levam consigo a aspiração de implementar o OP. A circulação institucional dos indivíduos facilita o deslocamento do OP de um lugar para o outro.

Esse mecanismo merece destaque, porque é a partir dele que operam os "embaixadores da participação" ou "embaixadores do OP". Esses atores compõem um elemento central da explicação do processo. São indivíduos que promovem ativamente o OP e que desempenham um papel determinante na inserção internacional do OP, em sua introdução nas organizações internacionais e na adoção da política em nível municipal. $O$ que os diferencia das categorias presentes na literatura, como brokers (Tarrow e McAdam, 2005) ou empreendedores de políticas (Kingdon, 1995), é o fato de que os Embaixadores não exercem um papel pontual no processo, mas são verdadeiros ativistas do OP, que circulam de um país a outro, de um município a outro e de uma instituição a outra. Mais especificamente, eles são o alto escalão que promove continuamente essa política pública. Acumulam um conjunto de atributos característicos: 1) detêm autoridade em relação ao OP, que pode ser de natureza política, teórica, prática ou técnica; 2) promovem o OP independentemente da instituição em que atuam; 3) têm ação contínua 
ao longo do processo. São indivíduos que atuam no contexto dos municípios, como prefeitos, secretários, acadêmicos (urbanistas e sociólogos), quadros de organizações internacionais, executivos de ONGs etc., que operam por vezes dentro e outras vezes fora das instituições. Os "embaixadores do OP" são também seus representantes e militantes da causa da democracia participativa. Podem ser considerados como embaixadores do OP: Tarso Genro, Raul Pont e Ubiratan de Souza, que atuaram na prefeitura de Porto Alegre; Yves Cabannes, no Programa de Gestão Urbana para a América Latina e Caribe da ONU; Victor Vergara e André Herzog, no Banco Mundial.

As macrodinâmicas do processo de difusão podem ser mais bem explicadas a partir de adaptações de propostas estilizadas presentes na literatura, especialmente aquelas que estão no campo das relações internacionais. O argumento sequencial do processo, que é fragmentado em "ponto de virada" (tipping-point), "transbordamento" (spillover) e "difusão massiva", compõe a meta narrativa a respeito da difusão global do OP. Essas etapas fazem parte das explicações na literatura sobre a difusão de normas internacionais (Finnemore e Sikkink, 1998), mas que também podem ser encontradas nos estudos do campo da epidemiologia, em particular na difusão de vírus, como o Ebola (Quammen, 2013). O ponto de virada pode ser considerado como o momento em que uma massa crítica aceitou e reconheceu o OP como uma política pública positiva e que deve ser adotada para realizar um "bom governo". O transbordamento consiste no processo intermediário em que ocorre uma difusão massiva, no sentido de que, a partir desse momento, o OP passa rapidamente de um indivíduo a outro, de uma instituição a outra, de uma região a outra, e assim por diante.

A combinação de explicações de escala macro e micro é uma estratégia emergente na análise da difusão internacional de políticas (Peck, 2012; Pal, Hadjiisky e Walker, no prelo). O uso é importante para compreender a escala de interação das múltiplas dinâmicas que levaram à difusão internacional do OP. O ciclo da difusão do OP inicia nos anos 1990, tendo como primeiro marco o encontro Habitat II, ocorrido em Istambul em 1996, quando Porto Alegre foi premiada como uma das melhores práticas de gestão urbana no mundo. Foi a partir desse momento que o OP passou a se internacionalizar, pois antes era conhecido especialmente entre cidades brasileiras e suas vizinhas no cone Sul. O ponto de virada, tipping-point, do processo de difusão ocorreu com a sucessão dos primeiros Fóruns Sociais Mundiais, de Porto Alegre, a partir de 2000. Nesse momento, o OP torna-se conhecido no mundo todo e se impõe como uma referência global da democracia participativa. A difusão massiva é fomentada especialmente nessa década, quando as organizações internacionais como a ONU, a União Europeia e o Banco Mundial passam a recomendar o OP, publicar manuais sobre essa política, organizar encontros internacionais para reunir pessoas interessadas no tema e financiar diretamente o desenvolvimento de novas experiências e o intercâmbio entre práticas já existentes. Nas próximas seções serão apresentadas as etapas desse processo em detalhe. 


\section{O ponto de virada: Porto Alegre e o Fórum Social Mundial}

Em janeiro de 2001, o editorialista do Le Monde Diplomatique, Ramonet, escreveu na capa da edição francesa do jornal que "o novo século começa em Porto Alegre". O autor defendia que a cidade tinha conhecido um desenvolvimento espetacular e que o segredo dessa conquista era o OP (Ramonet, 2001, p. 1). De acordo com Raul Pont, ex-prefeito de Porto Alegre, a presença dessa política de participação social foi um dos motivos que fizeram da cidade a sede do $\mathrm{FSM}^{3}$. O ex-prefeito também afirmou que havia um argumento defendido por um dos jornalistas do Le Monde Diplomatique que resumia a motivação geral para que o FSM ocorresse em Porto Alegre, e que nas palavras de Pont era essencialmente o seguinte: "em nenhum lugar tinha algo tão consolidado antineoliberalismo, nada era mais oposto ao neoliberalismo do que a experiência que a gente fazia aqui de OP, que era o contrário da antipolítica, da privatização, das desregulamentações, da ausência de Estado"4. A capital gaúcha se tornou o ícone da esperança de "um outro mundo possível", mais democrático, mais inclusivo e com mais justiça social. O Fórum era, antes de tudo, um ponto de encontro entre os movimentos sociais do mundo todo. Durante o evento se teciam relações e se expandiam as redes, facilitando o intercâmbio de ideias, técnicas e conhecimento e forjava uma agenda de ação transnacional. Porto Alegre, em particular, potencializou suas relações internacionais de modo exponencial. Em linhas gerais, o FSM foi também um espaço para a construção social da ideia do OP como um instrumento de radicalização da democracia.

Com a sucessão dos FSMs, forjou-se, a partir das autoridades locais no poder em Porto Alegre, uma ampla rede de "amigos" e interessados no OP. O Fórum das Autoridades Locais pela Inclusão Social e Democracia Participativa (FAL) é uma expressão desse movimento, no que diz respeito às autoridades locais, mas o FSM é mais amplo e inclui também ONGs, movimentos sociais, sindicatos, entre outras forças políticas organizadas. Com efeito, o porte do evento e sua dimensão internacional fizeram que, por um lado, muitas delegações estrangeiras visitassem e conhecessem o OP in loco. Ignácio Ramonet menciona esse movimento claramente ao dizer que "há alguns anos (...) Porto Alegre é uma forma de laboratório social que os observadores internacionais observam com um certo fascínio" (Ramonet, 2001, p. 1). Como afirmou um dos políticos entrevistados em Porto Alegre, "o que levou o Orçamento [Participativo] a ganhar o mundo foi o Fórum Social Mundial (...) em várias oficinas a gente apresentou a experiência, entregamos a literatura, inclusive publicamos algum material em inglês, espanhol, francês (sic) ${ }^{5}$. Por outro lado, especialistas de Porto Alegre viajavam apresentando o OP ou oferecendo workshops, como já ocorria desde meados dos anos

\footnotetext{
${ }^{3}$ Entrevista realizada com Raul Pont, Porto Alegre, 2011.

${ }^{4}$ Entrevista realizada com Raul Pont, Porto Alegre, 2011.

${ }^{5}$ Entrevista realizada com João Verle, Porto Alegre, 2011.
} 
1990. Ambos os movimentos contribuíram para aumentar o número de transferências e ampliar o alcance da visibilidade internacional do OP.

A partir do FSM ocorreu um incremento significativo nas experiências do OP, que até então podiam ser "contadas nos dedos". É preciso insistir no fato de que o ponto de virada não está localizado no primeiro FSM, mas trata-se de um breve processo que se instaura com a sucessão, pelo menos, dos primeiros três eventos (2001, 2002, 2003), que correspondem às edições que foram realizadas em Porto Alegre. No que diz respeito à "massa crítica de adotantes", não se trata somente de municípios, mas de atores de outra natureza, como organizações internacionais (ONU, União Europeia e Banco Mundial), ONGs, jornais internacionais, partidos, entre outros. Desse momento em diante, o OP engrena num movimento mais amplo em que múltiplos atores passam, cada um a seu modo, a promover o OP. Esse movimento fez que o dispositivo de governança participativa transbordasse do contexto local brasileiro e latino-americano e ganhasse o mundo.

A expansão efetivamente ocorre na Europa a partir de 2000. O aumento das experiências no velho continente é progressivo. Em 2002 são cerca de 20, em 2005, chegam a 55 e ultrapassam uma centena em 2008 (Sintomer, Herzberg e Röcke, 2008, p. 38). Um conjunto de capitais adota o OP: Paris, Roma, Londres, Lisboa e Berlim. A despeito de ter ocorrido recentemente um refluxo nas experiências, com mudanças políticas em muitos municípios com experiências fortes de OP, a Polônia, mediante um incentivo nacional, está aumentando significativamente a implementação do dispositivo. Na África, desabrocham experiências em Moçambique, Senegal e Camarões. Entram em cena outras instituições internacionais mais estruturadas e formais: as organizações internacionais. A ONU, a União Europeia e o Banco Mundial passam a atuar de forma mais incisiva na promoção do OP. No Peru, uma lei nacional foi criada, obrigando os municípios a implementar OPs, o que provoca um incremento em escala das experiências; o mesmo ocorreu no Equador e na República Dominicana.

\section{Tabela 1}

\section{Estimativa da expansão dos OPs no mundo 6}

\begin{tabular}{|l|c|c|c|}
\hline Região & $\mathbf{2 0 0 0 - 2 0 0 3}$ & $\mathbf{2 0 0 8 - 2 0 1 0}$ & $\mathbf{2 0 1 3}$ \\
\hline OP na América Latina e no Caribe & 200 & 920 & 1.120 \\
\hline OP na Europa & 20 & 296 & 1.317 \\
\hline OP na África & 3 & 110 & 211 \\
\hline Total & 223 & 1.326 & 2.648 \\
\hline
\end{tabular}

Fonte: Elaboração própria com base em fontes secundárias e na literatura acadêmica e técnica.

\footnotetext{
${ }^{6}$ As informações a respeito do OP no mundo são imprecisas, mas são as únicas disponíveis até o momento. A literatura acadêmica utilizada se baseou em Cabannes (2006), Porto de Oliveira (2016), Wampler (2008), Sintomer, Herzberg e Allegretti (2013) e Sintomer, Herzberg e Röcke (2008).
} 
A partir do "ponto de virada" intervém um descolamento forte entre "experiência original" e seus "descendentes". A política de participação social que se difunde, em seus aspectos técnicos e ideológicos, se transforma ao longo do processo, sendo modificada pelos transmissores e pelos adotantes em relação ao contexto no qual são implementadas. Em 2012, o OP é um dispositivo polimorfo, levado a cabo por instituições diversas. Além disso, surgem inovações no que diz respeito à tecnologia (savoir-faire, técnicas e desenho institucional) do OP. Há municípios que se especializam em setores de políticas públicas, como o OP Habitação de Belo Horizonte (Brasil), ou em contextos multiétnicos, como o OP de Cotacachi (Equador), ou ainda na tecnologia da informação e comunicação, como no sul do Kivu (na República Democrática do Congo) ${ }^{7}$.

O ponto de virada na difusão do OP é um marco que representa a passagem da experiência local à difusão massiva. O processo que leva à proliferação em escala planetária do OP é estimulada por uma pletora de atores numa relação interativa entre indivíduos e instituições. Porto Alegre continua aos olhos do mundo a capital da democracia.

\section{A difusão massiva: o OP e as organizações internacionais}

\section{O Programa de Gestão Urbana para a América Latina e Caribe (PGU-ALC)}

A Organização das Nações Unidas é a instituição internacional que há mais tempo está implicada no processo de circulação do OP. As formas de operação da ONU na promoção do OP são diversas, mas está concentrada na Agência para Assentamentos Humanos, a UN-Habitat. Encontraram-se também registros de programas de cooperação financiados por outras agências como Unicef, PNUD e Unifem, em diversos momentos e países, para estimular experiências de OP na América Latina e na África, por exemplo ${ }^{8}$. A entrada do OP na agenda da ONU ocorreu em 1996 na segunda conferência para assentamentos humanos, Habitat II, em Istambul, na Turquia, quando a instituição conferiu a Porto Alegre a distinção de "Melhor Prática". A indicação do OP foi feita pelo Instituto Brasileiro de Análises Sociais e Econômicas (Ibase) e pela Prefeitura de Porto Alegre (Utzig e Guimaraens, 1996, p. 51). A "chancela" da ONU tem um forte peso na legitimação internacional do OP. Por seu turno, o reconhecimento externo foi desde então utilizado sistematicamente para reforçar a aceitação interna do OP na cidade de Porto Alegre. Esse prêmio sempre é repetido pelos autores e defensores dessa política de participação social.

\footnotetext{
7 Entrevistas realizadas com quadros da administração pública: de Belo Horizonte, 2013; de Cotacachi, 2012; de Kivu do Sul, 2012.

8 O Unicef financiou: uma das primeiras viagens de membros da sociedade civil de Cotacachi para formação em Porto Alegre, um programa que introduziu as primeiras experiências de OP no Cabo Verde e um programa para OP e crianças no Senegal. A Unifem foi atuante na República Dominicana. O PNUD apoiou parte das experiências na África.
} 
A ONU apresenta o OP como uma política idônea para promover os Objetivos de Desenvolvimento do Milênio (Urban Management Program, 2004), aprimorar a gestão pública nas coletividades locais e lutar contra a pobreza ${ }^{9}$. Entre o final dos anos 1980 e o início dos anos 1990, junto ao processo de organização do segundo encontro da Habitat, a ONU idealizou duas frentes de ação para aprimorar a administração pública local. Da sede das Nações Unidas em Nairóbi, no Quênia, forjou-se a ideia de que, para enfrentar a rápida expansão da população urbana, era preciso se afastar de receitas de políticas públicas predefinidas, selecionando um conjunto de práticas que pudessem simplesmente servir de "farol" ou fonte de inspiração para a gestão das coletividades territoriais. A ONU-Habitat passou então a buscar políticas municipais bem-sucedidas ao redor do planeta, avaliá-las e laurear algumas delas como "Melhores Práticas"10.

Outra frente de ação da ONU-Habitat foi justamente a criação dos Programas de Gestão Urbana (PGU), instituídos em 1986. Os programas surgiram a partir de uma parceria entre UN-Habitat e o PNUD (Programa das Nações Unidas para o Desenvolvimento), com auxílio de agências externas, que operaram como centros de produção de conhecimento técnico, promotores de práticas inovadoras e, também, no fomento de redes transnacionais de municípios e na realização de pressão local e nacional em matéria de políticas urbanas. Os objetivos gerais do PGU são: contribuir para que as coletividades territoriais em países em desenvolvimento possam alcançar o crescimento econômico, desenvolvimento social e a redução da pobreza. A proposta organizacional dos PGUs foi criar um programa global com escritórios descentralizados, para ter maior impacto nas regiões e independência da sede. Foram estabelecidos quatro escritórios e dois subescritórios regionais, além do escritório global em Nairóbi ${ }^{11}$.

Na América Latina, o PGU-ALC foi instalado no Equador, em Quito. A coordenação foi exercida durante os anos de operação por Yves Cabannes e seu assessor regional Jaime Vásconez. Cabannes tinha ampla experiência na área de planejamento urbano em países em desenvolvimento. Passou por uma das "Grandes Écoles" na França e defendeu sua tese de doutorado sobre as determinações do espaço urbano no Iraque, na Universidade da Sorbonne. Antes de se tornar coordenador do PGU-ALC, o especialista havia trabalhado na ONG Gret e no think-tank Cirad, ambos empenhados com ações em países em desenvolvimento. Em sua trajetória, deslocava-se muito para missões de campo. Havia passado pelo Brasil, instalando-se durante certo período em Fortaleza, onde foi codiretor do Cearah Periferia ${ }^{12}$. Sua vinda para o Brasil coincidiu com o processo

\footnotetext{
9 O OP como um instrumento para promover os ODMs (Objetivos do Milênio) é sistematicamente mencionado nos prefácios dos manuais produzidos pela ONU.

${ }^{10}$ Entrevista com Alberto Paranhos, videoconferência São Paulo-Curitiba, 2012.

${ }^{11}$ Respectivamente: o Escritório Regional para a África em Abidjan, Costa do Marfim e o Escritório Subregional para o leste e o sudeste da África em Johanesburgo, África do Sul; o Escritório Regional para a Ásia e o Pacífico em Bangcoc, Tailândia, e o Escritório Sub-Regional para a Ásia do sul, em Nova Délhi, na Índia; o Escritório Regional para os estados árabes no Cairo, Egito; o Escritório Regional para a América Latina e Caribe, em Quito, Equador. Ver UN-Habitat, disponível em: <http://www. unhabitat.org/content.asp?typeid=19\&catid=374\&cid=185>. Acesso em: 7 mar. 2013.

12 O Cearah Periferia também foi um projeto que recebeu a láurea de boa prática pela ONU em 1996.
} 
de democratização e a promulgação da Constituição em 1988. Foi então que o especialista teve contato com movimentos sociais emergentes e experiências inovadoras de gestão pública e de participação e democracia. Nesse período conheceu o OP na cidade de Porto Alegre, veio a se especializar no assunto, tornando-se mais tarde um "embaixador do OP".

A presença de Yves Cabannes foi fundamental para a difusão do OP a partir do PGU-ALC, por sua capacidade de articulação transnacional, conhecimento do campo na América Latina e compreensão das instituições na Europa. A ação do coordenador do PGU-ALC não se deu somente no âmbito da ONU, mas se estendeu também ao programa URB-AL, que é apresentado adiante, e na construção de redes em geral, como foi descrito anteriormente no caso de Belo Horizonte. O PGU-ALC foi mantido em atividade em Quito até 2004, quando foram fechados os escritórios dos PGUs, após uma decisão da UN-Habitat, e se passou a trabalhar com redes regionais, por meio de instituições de âncora. Nesse mesmo período foi implementado o escritório descentralizado da UNHabitat em Quito. As instituições âncora se tornaram catalisadoras regionais no processo de difusão do OP, sobretudo na África, com o Municipal Development Partnership for Eastern and Southern Africa (MDP-ESA) no Zimbábue e a Environnement et Developpement (Enda Ecopop) no Senegal, que se mostraram importantes instituições regionais para a difusão do OP na África anglófona, no que diz respeito à primeira, e francófona, em relação à segunda (Porto de Oliveira, 2016). O PGU-ALC trabalhava com um conjunto variado de políticas em sua agenda, como a agricultura urbana, políticas de gênero e, justamente, o OP. Vale notar que a experiência de Porto Alegre é uma referência em matéria de $\mathrm{OP}$, mas não era a única a ser recomendada. O programa sediado em Quito serviu como um catalisador regional da experiência, no sentido de que acelerou o processo de difusão regional. O PGU-ALC foi um lócus de reflexão, produção, formação de quadros e difusão do OP.

A ONU serviu, portanto, como uma instituição legitimadora do OP e contribuiu para sua difusão de forma direta por pelo menos dois canais: a produção de conhecimento e o estímulo às transferências por meio de assistência técnica e encontros internacionais. Com efeito, o PGU-ALC produziu extensa literatura técnica sobre o OP, pois ao longo dos anos passou a sistematizar as experiências, as dificuldades encontradas em diversos campos e as melhores soluções para os problemas relativos à implementação do OP. As orientações que marcaram o trabalho do PGU-ALC foram diversas: os Objetivos do Milênio, as questões mais frequentes sobre o OP e os diversos manuais.

Em 2000, o PGU-ALC promoveu, com outros parceiros, em Villa El Salvador no Peru, o I Encontro Internacional do Orçamento Participativo, que contou com a presença de representantes dos municípios de Porto Alegre e Santo André (Brasil), Montevidéu (Uruguai) e Guayana (Venezuela). Foi um movimento para lançar a circulação do OP na 
região andina. Na América Latina havia ainda um conjunto pequeno de experiências na época, aproximadamente 80 , sendo a maior parte destas concentradas no Brasil.

Nesse encontro, Cabannes afirmou que "o orçamento participativo não é uma moda, nem uma nova [p]alavra (sic) na política, nem uma receita. O que está em jogo é uma reafirmação do Estado no âmbito municipal, do governo local como regulador e redistribuidor de riqueza" (Programa de Gestão Urbana, 2001, p. 46). Em seu discurso Cabannes também insistiu no fato de que, "se não temos claro que o valor agregado [do OP] é a redução das desigualdades, a redução da segregação espacial e social, então estamos tentando aplicar um método, mas sem ver para onde nos dirigimos" (Programa de Gestão Urbana, 2001, p. 46).

A organização de encontros internacionais sobre OP foi uma prática que se tornou cada vez mais frequente, aumentando exponencialmente a partir dos anos 2000. Ações dessa natureza, bem como a cooperação internacional para intercambiar ideias e conhecimento sobre o OP e a realização de advocacy por parte das autoridades locais para promover essa política, também foram constantes. Cabannes menciona, no referido encontro em Villa El Salvador, o seguinte:

o tema do orçamento participativo e sua contribuição à democratização da gestão das cidades (...) é uma agenda técnica e, como parte de organismos internacionais de cooperação técnica representando a ONU em um nível regional, posso contribuir nesse nível. Mas outra instância que nos parece muito importante resgatar é a da representação política que está presente aqui. Temos muitos prefeitos, muitas cidades presentes e isso é um lobby importante (Programa de Gestão Urbana, 2001, p. 78).

Além disso, também havia uma prática de assinar protocolos de intenção entre os municípios, como forma de induzir a adoção do OP. Isso vale para a região latinoamericana, no início da expansão das experiências, mas também para a Europa ${ }^{13}$ e para a região da África Subsaariana.

Os Fóruns Urbanos Mundiais (FUM), promovidos pela UN-Habitat, foram outros espaços que se tornaram emblemáticos. As sessões sobre o OP estiveram constantemente na programação e esse ambiente foi fonte de inspiração para muitos implementarem o dispositivo alhures. Em 2004, o então governador do estado do Rio Grande do Sul, Olívio Dutra, esteve presente no FUM em Barcelona. Esse momento coincidiu com o processo de "transferência em escala" do OP do nível municipal ao estadual. No FUM de 2010 no Rio de Janeiro dois atores importantes tiveram a ideia de adotar o OP em Makhado na África do Sul (Porto de Oliveira, 2016).

A presença do PGU-ALC fez que surgisse nos Andes, entre Equador e Peru, um polo de irradiação do OP. Nas palavras de Jaime Vásconez, "se este programa [o PGU-

\footnotetext{
${ }^{13} \mathrm{Na}$ França, Saint-Denis foi pioneira ao assinar um protocolo de intenções com Porto Alegre em 1998 visando à transferência do OP. Em Portugal a prática também foi realizada entre municípios portugueses e moçambicanos (conversa informal com Nelson Dias, coordenador da ONG portuguesa In Loco, 2013).
} 
ALC] teve algum êxito, foi ter promovido o OP em nível regional e global ${ }^{14}$. As experiências peruanas em Ilo e Villa El Salvador, bem como as equatorianas em Cotacachi e Cuenca, foram inovadoras e ganharam o mundo. A ação do programa foi importante, se não decisiva, na construção de um conjunto de práticas na região latinoamericana, bem como na inserção das cidades numa rede transnacional mais ampla, o que facilitou sua divulgação. A ação com Villa El Salvador, e seus desdobramentos, fica clara quando Yves Cabannes explica que, entre suas ações, esteve "o esforço (...) de capacitar várias equipes para reproduzir o OP no Peru, onde começou em Villa El Salvador"15. O PGU-ALC constituiu um lócus de encontro, ação e formação de muitas pessoas, militantes e técnicos, que, em suas trajetórias sucessivas, levaram seu aprendizado consigo promovendo a propagação do OP. O coordenador do programa também afirmou que muitas pessoas que passaram pelo PGU-ALC tornaram-se quadros de agências da ONU, prefeitos, quadros de ONGs sociais ou acadêmicos.

As ações do PGU-ALC se entrelaçam com as de outras instituições internacionais, como o Banco Mundial, agências de cooperação internacional de Estados e a União Europeia. A UN-Habitat também esteve envolvida, mais tarde, no momento da Constituinte no Equador no final da primeira década deste século ${ }^{16}$. A instituição promovia a inclusão de assuntos relacionados às cidades e às questões urbanas. Entre elas, a criação da lei sobre os OPs, articulada pelo escritório local e apoiada pela sucursal regional da UN-Habitat. A ação do PGU-ALC, a força das experiências latino-americanas e as energias mobilizadas por um conjunto de prefeitos motivados a participar ativamente de congressos internacionais, combinadas, contribuíram para fazer da América Latina um polo irradiador do OP.

Quando o PGU-ALC foi encerrado, surgiu uma instituição chamada Centro Internacional de Gestão Urbana (Cigu), uma ONG internacional com base em Quito e coordenada por Jaime Vasconez. O Cigu herdou a produção e o conhecimento acumulado do PGU-ALC e em alguma medida dá continuidade ao seu trabalho. A atividade do Cigu foi realizada em três frentes principais. Em primeiro lugar, colaborando com a sede da UN-Habitat em Nairóbi na produção de material técnico e capacitação no que se refere ao OP, para a África, trabalhando diretamente com a ONG Enda-Ecopop e o MDP-ESA. A segunda frente de trabalho foi assumir, com o programa URB-AL, o papel que já havia sido indicado pelo PGU-ALC. A última frente foi um projeto estabelecido com o Instituto do Banco Mundial para a difusão do OP em nível global. A seguir será apresentado o envolvimento da União Europeia com o OP.

\footnotetext{
${ }^{14}$ Entrevista realizada com Jaime Vásconez, Quito, 2012.

${ }^{15}$ Entrevista realizada com Yves Cabannes, Dacar, 2012.

${ }^{16}$ Entrevista realizada com Alberto Paranhos, videoconferência São Paulo-Curitiba, 2012.
} 
A ação da União Europeia em relação ao OP se deu em grande parte com o programa URB-AL, que financiou diretamente uma rede sobre o OP coordenada por Porto Alegre. Entretanto, existem projetos europeus realizados a respeito do OP com financiamento da União Europeia, captados por diversas instituições governamentais e não governamentais ${ }^{17}$. Nesta subseção será abordado somente o programa URB-AL, em particular a Rede-9. Em 1995 foi lançada a primeira fase do programa URB-AL da União Europeia. Um projeto ambicioso e pioneiro de cooperação descentralizada, cujo objetivo era aproximar as cidades europeias e latino-americanas. O propósito subjacente ao programa era estimular o intercâmbio de conhecimento técnico em matéria de administração urbana entre os municípios, de modo a melhorar a vida dos cidadãos e estabelecer "boas práticas" de governança local.

Na primeira fase, em meados dos anos 1990, a União Europeia abriu um edital para financiar uma rede temática intitulada "A democracia na cidade". O município de Porto Alegre, que já havia acumulado alguns anos de experiência com o OP, era um dos favoritos a vencer o edital, que tornaria possível a coordenação de uma ampla rede de projetos e contribuiria para a difusão do dispositivo a partir da capital gaúcha ${ }^{18}$. Todavia, Porto Alegre não obteve sucesso dessa vez.

Naquela época Porto Alegre ainda não havia alcançado prestígio internacional suficiente para sediar grandes projetos internacionais, a despeito de sua experiência e dos resultados do OP. Esse ainda era um momento de ascensão do OP, mas não de spillover, ou seja, de difusão massiva. Nos anos 1990, a despeito do prêmio outorgado pela UN-Habitat, Porto Alegre ainda não se beneficiava de grande reconhecimento externo, especialmente na União Europeia, onde havia uma agenda conservadora ${ }^{19}$, sendo o OP admirado especialmente por prefeitos do Partido Comunista Francês (Porto de Oliveira, 2010). Os "embaixadores do OP" foram construindo pouco a pouco a legitimidade e o prestígio internacional dessa política de participação social, por meio de transferências pontuais às cidades na América Latina e na Europa, da organização de eventos, do Fórum Urbano Mundial ao Fórum Social Mundial, da produção de literatura técnica, política e acadêmica.

Já na segunda fase do programa URB-AL, foi designada uma rede "para Porto Alegre", como afirmou um de nossos entrevistados. Essa rede veio a se chamar justamente Financiamento Local e Orçamento Participativo, a Rede-9. O programa da União Europeia se entrelaça aqui com uma rede preexistente que havia sido tecida por meio do PGU-ALC. Cabannes foi consultor para a Rede-9 e autor de parte do Documento

\footnotetext{
${ }^{17}$ O Fundo Andaluz, por exemplo, esteve à frente do FAL, e também ONGs como a Sodepaz e a Xarxa financiadas por fundos europeus incentivaram experiências de OP no Equador.

18 Depoimento de uma de nossas entrevistas realizadas em Paris em 2007.

19 Entrevistas realizadas com dois especialistas que optaram por permanecer anônimos, um de Madri, em 2012, outro de Dakar, em 2013.
} 
de Base, o relatório central do projeto. A rede foi aproveitada para expandir o OP com pequenos projetos. Ademais, serviu para o financiamento de projetos de OP temático e a realização de estudos de caso. Na segunda fase, as redes temáticas tinham um coordenador ou piloto da rede, isto é, a cidade que apresentava o projeto, que, no caso de Porto Alegre, foi a Rede-9. Em seguida, uma vez aprovado o projeto, as redes tinham a possibilidade de criar sub-redes, de modo a trabalhar com "Projetos Comuns". Nesse sentido, cidades com questões semelhantes podiam trabalhar juntas. O período do programa URB-AL é um momento de impacto com vários projetos relacionados ao OP.

O programa URB-AL teve êxito em fortalecer as experiências em termos técnicos, transferir conhecimento e estabelecer redes mais fortes, além de criar uma sinergia peculiar ao longo dos cinco anos de projeto. O programa aconteceu numa dinâmica de intercâmbio entre Europa e América Latina. Ademais, as prefeituras pequenas, com orçamentos baixos, puderam obter recursos para investir em suas áreas específicas de participação, como foi o caso de Cotacachi, que desenvolveu um projeto sobre o OP em municípios multiétnicos e pluriculturais (Porto de Oliveira, 2016).

O Cigu foi um dos principais consultores externos do programa URB-AL. A ONG baseada em Quito esteve presente em quatro dos seis projetos do programa URB-AL. De acordo com nossos entrevistados, Cabannes foi "o ponta de lança do projeto" e ele "carregou a rede nas costas" 20 . O programa URB-AL foi um projeto enriquecedor para as transferências do OP, por um lado, e para a consolidação e projeção das experiências, por outro. Por meio desse programa foram feitos diversos estudos de caso, que serviram para compreender e avaliar melhor as dimensões internas das experiências de OP e divulgar seus resultados.

A Rede-9 do programa URB-AL foi, durante cinco anos, um ponto central para a conexão de autoridades locais envolvidas com o OP e para a formação de especialistas. Nesse momento também existiam outras redes de autoridades locais, como o Fórum das Autoridades Locais pela Inclusão Social e Democracia Participativa (FAL), que também incorporavam o tema do OP. Com o URB-AL, essas redes foram alavancadas. Havia recursos no plano internacional para estimular a difusão do OP. É possível afirmar que as transferências adquiriram maior força com o programa URB-AL. A passagem por um programa de cooperação técnica da União Europeia contribuiu para dar ainda maior legitimidade internacional ao OP. O programa teve, ainda, desdobramentos importantes, como o impulso ao Observatório Internacional da Democracia Participativa, no plano externo, e a Rede Brasileira de Orçamentos Participativos ${ }^{21}$, no plano interno, ambos pensados como forma de dar continuidade às bases sedimentadas pelo URB-AL.

Após esse longo trabalho com as relações entre Europa e América Latina em torno do OP, chegou o momento de passar às articulações mais intensas de cooperação entre os municípios de países em desenvolvimento, em geral, e do Sul, em particular. O

\footnotetext{
${ }^{20}$ Entrevista realizada com um dos responsáveis pelo Programa URB-AL na Prefeitura Municipal de Porto Alegre, Porto Alegre, 2011.

${ }^{21}$ Entrevistas com: Jaime Vásconez, Quito, 2012; Claudineia Jacinto, Belo Horizonte, 2013.
} 
Banco Mundial, que será apresentado na próxima seção foi fundamental para traçar essa ponte.

\section{O Banco Mundial em ação}

Ainda que por razões diferentes da nossa, o Banco Mundial tem sido o maior propagador da ideia [do Orçamento Participativo]

Raul Pont (1999)

Em outubro de 1996 ocorreu uma conferência em Washington, na qual foram apresentadas e discutidas 20 experiências de cooperação entre sociedade civil e governo na América Latina. O OP da cidade de Porto Alegre obteve destaque e foi considerado uma das experiências com maior potencial de impacto na sociedade. Esse foi o primeiro registro encontrado na pesquisa sobre o reconhecimento do OP pelo Banco Mundial ${ }^{22}$. Dois anos mais tarde um Seminário Internacional a respeito do tema da Democracia Participativa foi realizado em Porto Alegre, contando com patrocínio do Instituto de Desenvolvimento Econômico do Banco Mundial ${ }^{23}$, entre outros parceiros. 0 evento teve a presença de 40 participantes e cinco observadores, oriundos de nove países das Américas (Navarro, s.d.). Se a ONU, com o PGU-ALC, ampliou o OP na América Latina e o URB-AL da União Europeia consolidou as relações com a Europa, a participação do Banco Mundial contribuiu para a adoção do OP nos países do Sul, especialmente nos da África.

O reconhecimento do OP pelo Banco Mundial, e sua consequente recomendação e promoção, é um movimento inusitado. As experiências de OP em sua origem em Porto Alegre, e outras na América Latina e Europa, estiveram fortemente associadas à ideia de transformação social e à radicalização da democracia, que, nas palavras de José Eduardo Utzig e Rafael Guimaraens (1996, p. 51), se resume no seguinte, o "Orçamento Participativo (...) é um elemento que está na raiz de um projeto político de governo que ambiciona democratizar radicalmente o Estado e a Sociedade" e, além disso, pode ser interpretado como uma inovação institucional idônea para "romper com o abismo que separa o Estado e a Sociedade e para reconstruir permanentemente a legitimidade das decisões do governo".

As relações entre as autoridades locais que governaram Porto Alegre e o Banco Mundial são ambíguas e mudaram ao longo do tempo, ganhando maior proximidade nas

\footnotetext{
${ }^{22}$ Em maio do mesmo ano o caso do OP de Porto Alegre havia sido apresentado em um workshop regional sobre administração pública patrocinado por diversas instituições internacionais: o Banco Mundial, a OEA e a agência espanhola de cooperação internacional.

${ }^{23}$ O Instituto de Desenvolvimento Econômico foi fundado em 1955 e desde 2000 é chamado de Instituto do Banco Mundial. As atividades de competência estão envolvidas na produção e na disseminação de conhecimento; dentre suas atividades estão a publicação de material de informação e a realização de cursos de capacitação e treinamento (<http://wbi.worldbank.org/wbi/about/strategy>. Acesso em: 29 ago. 2013).
} 
gestões mais recentes. Um entrevistado de uma ONG de Porto Alegre classificou a política do Banco Mundial em relação ao OP como uma "ação mercantilista"24. Outros criticaram as transferências promovidas pelo Banco Mundial, argumentando que a instituição tratava do OP como uma tecnologia, sem considerar as dificuldades do contexto, como no caso da Bósnia, tornando difícil assim o enraizamento das experiências ${ }^{25}$.

O que fez com que o Banco Mundial, ao mesmo tempo que pôde representar um projeto político "neoliberal", empreendesse ações destinadas à promoção do OP como política de governança participativa a ser aplicada nos governos locais em países em desenvolvimento? Há uma diferença entre o OP que é promovido pelo Banco Mundial e os iniciadores da experiência em Porto Alegre e em um conjunto de prefeituras progressistas na Europa e na América Latina. Metaforicamente poderia ser afirmado que o OP defendido pelo Banco Mundial não carrega o "espírito de Porto Alegre" descrito na seção anterior, "O ponto de virada: Porto Alegre e o Fórum Social Mundial", isto é, o seu caráter político e ideológico como um dispositivo de transformação social e radicalização da democracia. Paradoxalmente, as ações e declarações do Banco Mundial foram utilizadas pelas autoridades locais e pela imprensa de Porto Alegre como fonte de legitimação interna do OP ao longo dos anos 1990. Ademais, a mídia, bem como a literatura acadêmica, faz alusão ao fato de que o Banco Mundial recomenda o OP para fortalecer a credibilidade desse dispositivo. O Banco Mundial também financiou programas sociais e projetos de construção de infraestrutura na cidade de Porto Alegre (Fernandes, 2000, p. 54).

É possível afirmar, como defendem certos autores, que o Banco Mundial recomenda o OP como uma espécie de "prescrição global", ou seja, que os municípios em geral deveriam adotá-lo (Goldfrank, 2012). Todavia, é mais complicado argumentar que tenha ocorrido uma cooptação do OP pelo Banco Mundial. Essa instituição é complexa e tem uma ação multifacetada composta por dimensões política, intelectual e financeira e ainda uma posição singular de emprestador, formulador de políticas públicas e difusor de ideias e conhecimento (Pereira, 2010). A entrada do OP no Banco Mundial passou por diferentes momentos e essa política de governança participativa se tornou um dispositivo técnico, um instrumento de gestão pública, que pode ser aplicado em qualquer contexto. Poderíamos dizer que o OP passou por um processo de "destilação ideológica".

As ideias e os interesses que compõem os traços da ação do Banco Mundial na promoção do OP se borram em suas múltiplas agendas, agências e projetos. As iniciativas do Banco Mundial na promoção do OP partem de origens diferentes, como do Instituto do Banco Mundial ou do Departamento de Assuntos Sociais, ou, ainda, fazem parte de projetos mais amplos da Associação Internacional para o Desenvolvimento (AID). Essencialmente, "para o Banco Mundial o OP é um instrumento para melhorar as

\footnotetext{
${ }^{24}$ Entrevista realizada com membro da sociedade civil, Porto Alegre, 2011.

${ }^{25}$ Entrevistas e intervenções de especialistas em Porto Alegre e Brasília. A respeito desta última, ver Cebrap, 2011.
} 
instituições locais e está associado a princípios como o da 'boa governança', transparência, empowerment e accountability" (Shah, 2007). Os projetos do Banco Mundial na promoção do OP também estão orientados para "instaurar uma mudança de comportamento nos responsáveis locais" (World Bank, 2009, p. 10), como indica o relatório publicado pela instituição sobre a implementação desse dispositivo em Madagascar.

Ademais, os interesses que permeiam o Banco Mundial na promoção do OP são muito diversos e se associam também a princípios e agendas mais amplas como os Objetivos do Milênio e a luta contra a pobreza, a construção das instituições a partir dos territórios, ou seja, dos governos locais, e ainda os experimentos envolvendo participação social e uso das tecnologias da informação e comunicação (TIC), com projetos piloto na República Democrática do Congo no âmbito do programa ICT4GOV (Porto de Oliveira, 2016). A ação do Banco Mundial está presente ainda em diversos países que se estendem do Brasil à Bósnia, passando pelo Madagascar e a República Dominicana.

O OP inicialmente é objeto de um movimento de reconhecimento pelo Banco Mundial. Esse movimento é seguido por atividades de avaliação e recomendação. Nos dias atuais, essa instituição promove diretamente o OP. A presença do Banco Mundial e de suas agências na promoção do OP remonta a meados dos anos 1990 . O contato entre a experiência de OP, no caso de Porto Alegre, e o Banco Mundial é estabelecido por meio de encontros temáticos e do financiamento de projetos de infraestrutura e programas sociais na cidade. As relações entre Porto Alegre e o Banco Mundial foram incrementadas com delegações que se deslocaram da capital gaúcha para expor o OP em encontros temáticos organizados pelo Banco Mundial, da mesma forma que quadros dessa instituição se deslocaram a Porto Alegre para intervir em encontros sobre a democracia participativa.

O OP inicialmente estava inserido nas agendas gerais do Banco Mundial e, além de servir para conectar a sociedade civil ao Estado, havia uma percepção do dispositivo como uma ferramenta idônea para produzir resultados desejáveis nos processos de descentralização nos países em desenvolvimento. Preocupações com políticas de participação e infraestrutura estavam presentes no Banco Mundial pelo menos desde 1994 (Banco Mundial, 1994, p. 89 e 101). Nos anos 1990 o Banco Mundial seguiu uma estratégia de desenvolvimento orientada a partir das comunidades (Comunity Driven Development), que também tinha por princípio o desenvolvimento a partir do fortalecimento da sociedade em suas bases. Outra linha de ação consiste nas iniciativas para a descentralização do Estado. Em um documento escrito por George E. Peterson e publicado pelo Banco Mundial sobre os processos de descentralização, insistia-se que essas políticas deveriam "deslocar as autoridades do governo para perto do povo" (Peterson, 1997, p. 13). De acordo com Aycrigg (1998), Paul Wolfensohn, presidente do Banco Mundial (1995-2005), "defendia muito as iniciativas de participação em seus 
projetos e políticas públicas" (p. 1). O antigo presidente da instituição, em seu discurso anual em 1998, insistiu na dimensão da participação cidadã "como a chave para a sustentabilidade e a influência de longo período" (Wolfenson, apud Aycrigg, 1998, p. 1).

No Banco Mundial, Víctor Vergara, foi um dos quadros que estabeleceu a ponte entre as duas instituições, o Banco Mundial e a prefeitura de Porto Alegre. Vergara se interessou pelo OP como um instrumento de governança local ${ }^{26}$. Além disso, também contribuiu na organização do Seminário Internacional da Democracia Participativa em $1999^{27}$. Nesse encontro havia mais três funcionários do Banco Mundial em Porto Alegre ${ }^{28}$.

Nesse período, O OP foi introduzido em um programa de formação do Banco Mundial. O livro de Tarso Genro sobre o OP foi elaborado para ser incluído nesse programa, acrescido de um prefácio mais técnico e pedagógico. Em seguida, foi produzido um vídeo educativo sobre o OP, a partir do filme realizado por Martha Harnecker. Nas atividades do Banco Mundial são utilizados diversos materiais sobre o OP. A diferença entre produção original e o produto utilizado pelo Banco Mundial é que este passa por uma adaptação de modo a se tornar mais técnico e pedagógico e menos político e ideológico. Esse processo aparece de maneira clara nos relatos dos atores que estiveram envolvidos no processo ao exporem suas experiências, como o seguinte:

Eu sabia a respeito da abordagem, eu havia lido a respeito. Então nós estávamos fazendo um grande treinamento para a América Latina e eu sabia que (...) é uma reforma política fundamental que precisa ser feita para que a governança aconteça e nós sabíamos da experiência de Porto Alegre. Eu acho que Tarso [Genro] havia escrito este pequeno livro (...) e o prefácio da tradução (...) não era adequado para a capacitação, então eu liguei para o Tarso e perguntei a ele (...) se ele podia nos mandar o prefácio e se podíamos acrescentar uma nova versão, que fosse mais pedagógica (...). Isso foi antes do primeiro Fórum Social Mundial ${ }^{29}$.

Em outra passagem, o mesmo entrevistado também conta a respeito de sua relação com o trabalho de Martha Harnecker:

Eu também estive em contato com, eu conheci esta cientista social de Cuba, que era Martha Harnecker, ela tinha um filme e nós editamos esse filme e fizemos deste mais pedagógico também, porque era muito ideológico e nós fizemos este mais técnico e colocamos no contexto (...) então nós fizemos um vídeo explicando o orçamento participativo e foi uma espécie de início, era uma proposta razoável para a transparência, accountability, mas também para a eficiência.

\footnotetext{
${ }^{26}$ Entrevista realizada com Víctor Vergara, Washington, 2013.

27 Livro produzido pelo seminário (Becker, 2000).

${ }^{28}$ Eram eles: André Guimarães, Angela Griffin, Borges Mendes (Becker, 2000).

29 Entrevista anônima, Washington, 2013.
} 
A partir de meados dos anos 2000, dentro do Banco Mundial, aumentaram os projetos que continham o OP, embora o tema da participação já estivesse presente no Banco Mundial, sobretudo no setor social da instituição, há 15 anos $^{30}$. A incorporação do OP dentro da instituição foi feita a partir de um conjunto de atores específicos. Já sua ampliação seguiu dinâmicas próprias da instituição e da composição de seus projetos. À medida que o OP passava a ganhar espaço e reconhecimento na instituição, aumentavam os projetos que o incluíam como instrumento de gestão pública. Esse processo aumentou de tal forma que um de nossos entrevistados informou que não se sabia com precisão o número de projetos com esse dispositivo na instituição ${ }^{31}$.

Ao longo do tempo foram ingressando quadros especializados em $O P$, que haviam trabalhado no programa URB-AL ou com o OP em outras instituições ${ }^{32}$. Tiago Peixoto, por exemplo, especialista em governança aberta no Instituto do Banco Mundial (IBM), em sua carreira havia trabalhado com o tema da e-democracy no programa URBAL. Já outros passaram a integrar projetos com o OP pela primeira vez quando faziam parte do Banco Mundial ${ }^{33}$. André Herzog, arquiteto e urbanista, atualmente senior specialist do IBM, foi um dos principais quadros a estimular a difusão internacional do OP. Em sua trajetória trabalhou com o OP em instituições internacionais, "dentro e fora" do Banco Mundial. Além dos quadros especializados, foram produzidos manuais e relatórios sobre o OP especificamente ou sobre temas relacionados ao OP na instituição. Surgiu no Banco Mundial uma orientação própria do que é o OP, para que serve e como deve ser feito, assumindo uma característica menos ideológica e mais técnica. Ocorreu uma apropriação e uma tradução do dispositivo que surgiu em Porto Alegre.

Em diversos relatórios o Banco Mundial recomenda o OP, ação que pode ser observada a partir dos excertos abaixo.

Quadro 1

Recomendações de adoção do OP - Banco Mundial

\begin{tabular}{|l|l|}
\hline $\begin{array}{l}\text { Entering the 21st Century: } \\
\text { World Development Report } \\
1999 / 2000\end{array}$ & $\begin{array}{l}\text { As cidades devem ser proativas ao estabelecer mecanismos } \\
\text { formais, mas amigáveis, para encorajar parcerias que tragam } \\
\text { dinamismo e desenvolvimento. A experiência muito apreciada de } \\
\text { Porto Alegre, no Brasil, oferece um exemplo de como esse } \\
\text { processo pode ser iniciado (Banco Mundial, 2000, tradução } \\
\text { nossa). }\end{array}$ \\
\hline $\begin{array}{l}\text { Municipal Development in } \\
\text { Mozambique: }\end{array}$ & $\begin{array}{l}\text { Existem também exemplos internacionais de boa prática com os } \\
\text { quais Moçambique poderia aprender, incluindo aqueles de } \\
\text { Orçamento Participativo no Brasil (Banco Mundial, 2009, p. 13, } \\
\text { tradução nossa). }\end{array}$ \\
\hline
\end{tabular}

Fonte: Elaboração própria com base nos relatórios do Banco Mundial referidos na primeira coluna.

\footnotetext{
${ }^{30}$ Entrevistas realizadas com quadros do Instituto do Banco Mundial, Washington, 2013.

31 Entrevista anônima, Washington, 2013.

32 Entrevista realizada com: André Herzog, Washington, 2013; Tiago Peixoto, Washington, 2013.

33 Entrevista realizada com Sarah Keener, Washington, 2013.
} 
As políticas de governança participativa, bem como as iniciativas para a transparência no orçamento público são parte de uma agenda mais ampla que permeia os objetivos tanto do Banco Mundial quanto das Nações Unidas. O OP é entendido também como um instrumento para aliviar a pobreza. O Banco Mundial, como outras agências multilaterais, tem exercido esforços intensos nesse sentido.

A promoção direta do OP ocorre mediante a organização de encontros internacionais e o financiamento de projetos. Essas atividades estão, em muitos casos, inseridas em dinâmicas com agências nacionais de cooperação, como a da Suíça. Dois grandes eventos serviram para fomentar a difusão regional do OP, sobretudo na África, sendo um deles realizado em Porto Alegre e o outro em Durban na África do Sul, respectivamente em 2006 e 2008. O Cigu também participou da organização de ambos os eventos, bem como de iniciativas para estimular a difusão do OP em nível global.

Muitas das experiências africanas, que em certos casos ainda eram embrionárias, se desenvolveram com esses eventos. Em Durban, encontram-se boa parte daqueles que gostariam de implementar tal política ou que já haviam realizado o OP. E, como mencionado, é nesse encontro que foi criado um projeto entre Belo Horizonte e Maputo mediado pelo MDP-ESA do Zimbábue, com financiamento do Banco Mundial, para a produção de um manual de implementação do OP. O evento foi um lócus de reunião de quadros que nunca haviam ouvido falar de outras experiências, servindo como espaço de intercâmbio de ideias e tecnologias em matéria de $\mathrm{OP}^{34}$.

Além do financiamento de eventos, um conjunto de projetos piloto de OPs foi promovido pelo Banco Mundial na América Central, na República Dominicana e na África Subsaariana, como em Camarões, na República Democrática do Congo, em Moçambique e em Madagascar. A experiência do contexto malgaxe é particular por envolver a ação para um projeto piloto em nove municípios, dentre os quais uma parte teve um aumento significativo da receita após a descoberta de enormes jazidas de minério em seus territórios. Por seu turno, o incentivo do Banco Mundial com projetos piloto e uso de TIC gerou um efeito de contágio na região iniciado no Kivu do Sul na República Democrática do Congo, que, em seguida, foi para Yaoundé nos Camarões e, agora, também está em Nairóbi, no Quênia.

Nas ações acima mencionadas, a iniciativa parte do Banco Mundial (supply side), que oferece suporte ao desenvolver projetos diretamente com governos locais para implementar o OP. O movimento contrário também ocorre. Após um período em que o Banco Mundial simplesmente recomendava o OP aos governos locais nos países em que atuava, essa instituição, uma vez que se torna especialista em matéria de OP, passa a avaliar as experiências e a oferecer diagnósticos. Trata-se de um movimento cuja iniciativa é externa ao Banco Mundial (demand side), isto é, parte dos governos

\footnotetext{
${ }^{34}$ Diversas entrevistas com quadros políticos e técnicos do Moçambique e do Madagascar informaram a esse respeito.
} 
(municipal ou nacional) e chega a Washington por meio dos escritórios da instituição que se encontram alocados no país onde a solicitação é feita.

O Banco Mundial opera com seus quadros de Washington e aqueles que ficam em campo, bem como consultores locais ou regionais. A expansão dos projetos piloto fez com que os mesmos quadros circulassem implementando projetos semelhantes. Em parte dos casos, o OP está associado a projetos mais amplos da instituição. A ação do Banco Mundial na promoção do OP não é um fenômeno recente, como se insiste em parte da literatura acadêmica ou militante, mas a instituição acompanha o OP desde seus primórdios, em Porto Alegre e em outros municípios. O Banco Mundial se apropria progressivamente do dispositivo, compondo um quadro de especialistas em OP. Por meio do Instituto do Banco Mundial são desenvolvidos manuais, em muitos casos com apoios de funcionários de municípios com experiências avançadas de OP e acadêmicos. O envolvimento do Banco Mundial com o OP é fundamental para que as experiências ancorem no continente africano e importante para reorganizar um conjunto de experiências na América Latina. A ação da instituição ainda mostra uma orientação para a implementação do OP, que em certos casos é tida como uma condição para a concessão de recursos.

\section{Conclusão}

Este artigo teve por objetivo mostrar a transição entre o momento em que o OP ainda estava em busca de legitimidade internacional e a sua difusão massiva. Sua projeção internacional foi construída a partir de meados dos anos 1990, sobretudo por meio da ação de um conjunto de militantes, autoridades locais e quadros de organizações internacionais. Esse processo ocorreu até que o OP ganhou legitimidade internacional durante as edições do FSM e transbordou para outros países e instituições governamentais, intergovernamentais e não governamentais. É possível observar três grandes mecanismos operando entre o "ponto de virada" e a difusão massiva do OP: a indução institucional, a construção social e um papel determinante da circulação dos indivíduos. Os "embaixadores do OP" foram cruciais para que essa política pública começasse a fazer parte da agenda de instituições internacionais, as quais ampliaram o potencial de difusão por meio de ações diversificadas de cooperação entre América Latina, Europa e África Subsaariana. Além disso, há uma dimensão importante no que diz respeito ao projeto político subjacente ao OP, que foi traduzido e apropriado de formas distintas pelos atores que levaram e continuam levando esse dispositivo de uma instituição a outra, de um país a outro. Sem essas traduções o OP não teria tido o mesmo alcance em sua circulação, nem se inserido em organizações internacionais como o Banco Mundial.

O mecanismo de indução institucional pode ser observado a partir da ação das instituições internacionais que facilitaram a difusão massiva do OP. Trata-se de um 
mecanismo contínuo que se apresenta com intensidades heterogêneas que se estendem desde a indução por recomendação à imposição do OP como condição para a cooperação internacional. O trabalho do PGU-ALC foi significativo para consolidar conhecimento técnico e estabelecer parcerias em torno do OP na região da América Latina. O incentivo é visível em declarações, manuais e demais documentos das organizações internacionais. A título ilustrativo, em duas passagens na subseção "O Banco Mundial em ação", ficou claro que ele recomenda a adoção do OP conforme apresentado no Quadro 1. Por seu turno, o mecanismo também operou, de um lado, mediante o financiamento direto da cooperação para a transferência de conhecimento e, de outro, para a realização direta de experiências, como no Moçambique e Madagascar. O URB-AL foi um dos programas mais expressivos nesse sentido, ao colocar à disposição recursos para a cooperação entre países da América Latina e da Europa. Já os projetos do Banco Mundial estenderam as relações de intercâmbio até a África, ampliando o alcance da difusão.

A despeito da indução institucional, o OP não teria se difundido massivamente sem o trabalho precursor dos "embaixadores da participação". Muitas vezes estes têm influência dentro das instituições internacionais ou colaboram com elas. Os prefeitos de Porto Alegre, como Raul Pont e Tarso Genro, por exemplo, estiveram envolvidos em uma instituição internacional ao assumir a organização do FSM, que lançou o OP para uma dimensão planetária.

O mecanismo da circulação internacional de indivíduos com papel ativo na promoção do OP é onipresente. Destaca-se também o papel de Yves Cabannes, cuja participação foi fundamental não somente no PGU-ALC, mas também no programa URBAL. Por sua vez, é possível reconhecer o papel de Jaime Vásconez, que atuou no PGUALC, e em seguida no Cigu, oferecendo suporte e auxílio técnico no programa URB-AL, bem como nas primeiras relações com a África Subsaariana. As evidências encontradas na pesquisa apontam para o mesmo mecanismo no Banco Mundial. Essa instituição iniciou seu contato com o OP já em meados dos anos 1990 de maneira ainda tímida. Entre os pioneiros a trabalhar com o OP no Banco Mundial, esteve Victor Vergara, que "puxou" o OP para dentro da instituição, em particular para o IBM.

Uma década mais tarde já havia outros indivíduos trabalhando com o OP no Banco Mundial, como André Herzog, que, em sua trajetória, produziu uma avaliação do OP de Santo André, no Brasil, para uma instituição holandesa, junto ao IBM, e desenvolveu diversos projetos com o OP, nos Bálcãs, por exemplo, e estimulou sobretudo a promoção da cooperação entre América Latina e África Subsaariana em matéria de transferência do dispositivo. Além desses atores, muitos outros passaram por processos de capacitação e formação em matéria de OP no âmbito de seminários, oficinas e outras atividades. Com efeito, o PGU-ALC foi um primeiro lócus de formação de quadros, que seguiu com o programa URB-AL e, após uma década de cooperação internacional com o OP, constitui-se um grupo de especialistas internacionais. Alguns dos experts do Banco Mundial vêm de experiências internacionais prévias com o OP em 
outras instituições. Em seguida, os cursos de treinamento apoiados pelo Banco Mundial, especialmente na África, ajudaram a formar novos "embaixadores da participação".

O mecanismo da construção social esteve presente nos sucessivos FSMs, quando a imagem de Porto Alegre como a "capital da democracia" participativa foi forjada. 0 reconhecimento das instituições internacionais, como a ONU, a União Europeia e o Banco Mundial, também foi importante. Sem passar por grandes instituições, o OP não teria tido a mesma repercussão. O FSM fez com que o OP adquirisse maior visibilidade fora do Brasil. Em outras palavras, se antes o OP era conhecido somente por especialistas, prefeitos e militantes, especialmente aqueles de orientação progressista, com o FSM a política se popularizou em nível internacional. A "chancela" da ONU é importante para dar legitimidade à experiência. De fato, as organizações internacionais, muitas vezes, desempenham a função de apontar o caminho, em termos de políticas públicas, pelo qual os governos devem seguir. Vale notar que, no caso da União Europeia, não foi um processo simples, pois o OP só conseguiu atrair atenção após ter se consagrado internacionalmente e conseguido conquistar legitimidade e prestígio no início da década de 2000.

Apesar do sucesso alcançado pela experiência do OP e o fato de ter a OP se difundido massivamente ao redor do globo, seu elo inicial com Porto Alegre foi se perdendo ao longo do caminho. Ocorreu um processo de tradução de seu projeto político, isto é, de seu conteúdo ideológico. De fato, diferentemente do que se pregava durante o FSM, no qual a ideia subjacente à experiência do OP é a transformação social, por meio de uma experiência de radicalização da democracia, no caso das organizações internacionais essa dimensão foi diluída. Nestas últimas a parte técnica sobressai, há outros modelos que ganham destaque, muitos destes baseados em experiências concretas - como aquelas realizadas por cidades da América Latina e Europa - enquanto outros foram desenvolvidos pelos quadros da ONU ou do Banco Mundial em seus distintos projetos.

A difusão massiva do OP revela um movimento de ampliação da participação social nos processos de alocação orçamentária nas políticas públicas, que nos dias atuais está ocorrendo em escala global. Com este artigo ficou evidente que esse processo não corresponde a uma agenda de grupos e forças progressistas, mas que também está sendo realizado por instituições econômicas multilaterais. Ao circular pelo mundo, o OP se tornou uma política pública de conteúdo vazio e sua maleabilidade é um requisito indispensável para que esse processo se cumpra. De fato, é necessário que o OP seja adaptado para que sua transferência possa ocorrer em distintos contextos. Nesse processo, O OP passou a ser utilizado por muitos atores, de formas muito diversas daquela em que foi concebido originalmente em Porto Alegre, ao final dos anos 1980. Por um lado, o PT em Porto Alegre se valeu da "chancela" das instituições internacionais para legitimar sua prática internamente no Brasil e na cidade. Por outro, as mesmas instituições usaram e transformaram o modelo de Porto Alegre incorporando-o às suas 
agendas de ação mais amplas, de acordo com seus interesses específicos, incluindo-o em projetos destinados a outros países.

O OP foi traduzido para as organizações internacionais como um instrumento de gestão urbana. As ênfases dadas a ele pelas organizações analisadas no artigo são muitas. A título ilustrativo, há uma associação entre OP e promoção da Agenda-21 feita pela ONU. Já a União Europeia reconhece a importância de cooperação e o intercâmbio entre cidades. Nesse caso, todavia, como são os municípios que operacionalizam as transferências e a cooperação internacional, a dimensão política do OP nas relações entre os municípios pode ser mais ou menos forte, de acordo com quem coordena a rede. $O$ Banco Mundial destaca a luta contra a corrupção como um dos êxitos positivos do OP e realizou uma destilação do conteúdo ideológico do OP, para torna-lo mais técnico e passível de reprodução. É certo que não é possível fazer coincidir as visões dos indivíduos que estão promovendo o OP, a partir dessas organizações, com a perspectiva institucional mais ampla. O que pode ser afirmado com segurança é que o conteúdo político e ideológico original de Porto Alegre se modificou ao longo da difusão massiva dessa política de participação social e nos dias de hoje existe uma diversidade grande de OPs no mundo.

Osmany Porto de Oliveira - Departamento de Relações Internacionais Escola Paulista de Política, Economia e Negócios (EPPEN). Universidade Federal de São Paulo (Unifesp). Email: <osmanyporto@gmail.com>.

\section{Referências bibliográficas}

Allegretti, G.; Herzberg, C. El 'retorno de las carabelas': los presupuestos participativos de Latinoamérica en el contexto europeo, 2004. Disponível em:

<http://old.iepala.es/documentos_sevilla/6.pdf>. Acesso em: 9 set. 2015.

AYCRIGG, M. Participation and the World Bank: success, constraints, and responses. Social Development Papers, n²9, World Bank, 1998.

BANCO MUNDIAL. World development report: infrastructure for development. New York: Oxford University Press, 1994.

BECKER, A. J. A cidade reinventa a democracia. Porto Alegre, Prefeitura Municipal de Porto Alegre, 2000.

CABAnnes, Y. "Les Budgets Participatifs en Amérique latine: de Porto Alegre à l'Amérique Centrale, en passant par la zone andine, tendances, défis et limites". Mouvements, n 47-48, p. 128-138, 2006.

DEZALAY, Y.; GARTH, B. La mondialisation des guerres de palais: la restructuration du pouvoir d'Etat en Amérique Latine. Entre notables du droit et Chicago boys. Paris: Seuil, 2002.

DolowITZ, D.; MARSH, D. "Learning from abroad: the role of policy transfer in contemporary policy making". Governance, vol. 1, n 13, p. 5-24, 2000. 
Fernandes, R. B. Orçamento Participativo: construindo a democracia. Rio de Janeiro: Revan, 2000.

FINNEMORE, M.; SIKKINK, K. "International norm dynamics and political change". International Organization, vol. 52, n 4, p. 887-917, 1998.

GANUZA, E.; BAIOCCHI, G. "The power of ambiguity: how Participatory Budgeting travels the Globe". Journal of Public Deliberation, vol. 8, n², p. 1-12, 2012.

George, A.; Bennett, A. Case studies and theory development in the social sciences. Massachusetts: MIT Press, 2005.

GoldFRANK, B. "The World Bank and the globalization of Participatory Budgeting". Journal of Public Deliberation, vol. 8, n², p. 1-14, 2012.

Graham, E.; ShIPAN, C.; Volden, C. "The diffusion of policy diffusion research in political science". British Journal of Political Science, vol. 43, n³, p. 673-701, 2013.

HALL, P. "Policy paradigms, social learning, and the State: the case of economic policymaking in Britain". Comparative Politics, vol. 25, n 3, p. 275-296, 1993.

HASSENTEUFEL, P. "De la comparaison internationale à la comparaison transnationale, les déplacements de la construction des objets comparatifs en matière de politiques publiques". Revue Française de Science Politique, vol. 55, n 1, p. 113-132, 2005.

KInGDON, J. Agendas, alternatives and public policy. Harper Collins: New York, 1995.

LATOUR, B. La science en action: introduction à la sociologie des sciences. Paris: La Découverte, 2005.

MARCUS, G. E. "Ethnography in/of the world system: the emergence of multi-sited ethnography". Annual Review of Anthropology, n²4, p. 95-117, 1995.

NAVARRO, Z. "Relatório: Seminário Internacional sobre o Orçamento Participativo". Porto Alegre, s.d.

PAL, L.; HADJIISKY, M.; WALKER, C. Beg, borrow, steal or swallow? The micro-dynamics and macroeffects of contemporary policy transfers. Cheltenham: Edward Elgard, no prelo.

PECK, G. "Geographies of policy: from transfer-diffusion to mobility-mutation". Progress in Human Geography, vol. 35, nº 6, p. 773-797, 2012.

Peterson, G. E. Decentralization in Latin America: learning through experience. Washington: The World Bank, 1997.

Pereira, J. M. M. O Banco Mundial como ator político intelectual e financeiro: 1944-2008. Rio de Janeiro: Civilização Brasileira, 2010.

PONT, R. "Inicia-se troca de experiências democráticas". Correio do Povo, 10 nov. 1999.

PORTO DE OlIVEIRA, O. Le transfert d'un modèle de démocratie participative: paradiplomatie entre Porto Alegre et Saint-Denis. Paris: Collection Chrysallides, IHEAL Éditions, 2010.

. Embaixadores da participação: a difusão internacional do Orçamento Participativo. São Paulo: Annablume, 2016.

Programa de Gestão Urbana. I Seminário Internacional sobre o Orçamento Participativo. Quito, 2001.

QUAMmEN, D. Spillover: animal infections and the next human pandemic. New York: W.W. Norton \& Company, 2013. 
RAmonet, I. "Porto Alegre". Le Monde Diplomatique, n 562, jan. 2001. Disponível em: <https://www.monde-diplomatique.fr/2001/01/RAMONET/7707>. Acesso em: 9 set. 2015.

SAURUgGer, S.; Surel, Y. "L'Européanisation comme processus de transfert de politique publique". Revue Internationale de Politique Comparée, vol. 13, n², p. 179-211, 2006.

SChatz, E. (ed.). Political ethnography: what immersion contributes to the study of power. Chicago: The University of Chicago Press, 2009.

SHAH, A. (ed.). Participatory budgeting. Washington: World Bank, 2007.

Simmons, B.; DobBin, G.; GARRET, F. The global diffusion of markets and democracy. New York: Cambridge University Press, 2008.

Sintomer, Y.; Herzberg, C.; Allegretti, G. "Participatory budgeting worldwide: updated version". Dialog Global. Study n²5. Bona: Engagement Global, 2013.

Participatory Budgeting worldwide: an invitation to global cooperation dialog global. Study n० 25. Service Agency. Bona, 2013.

Sintomer, Y.; Herzberg, C.; RöCKe, A. Les Budgets Participatifs en Europe. Paris: Recherches, 2008.

Modelos transnacionais de participação cidadã: o caso do OP. In: DiAs, N. (org.). Esperança democrática: 25 anos de Orçamento Participativo no mundo. São Brás de Alportel: In Loco, p. 2644, 2013.

StRANG, D.; MeYer, J. W. "Institutional conditions for diffusion". Theory and Society, vol. 22, n 4, p. 487-511, 1993.

STRANG, D.; SOULE, S. "Diffusion in organizations and social movements: from hybrid corn to poison pills". Annual Review of Sociology, n² 24, p. 265-290, 1998.

TARRow, S.; McAdAM, D. Scale shift in transnational contention. In: DelLA PORTA, D.; TARROW, S. (orgs.). Transnational protest and global activism. Lanham: Rowman \& Littfeld, p. 121-150, 2005.

Urban Management Program. Participatory Budgeting: conceptual framework and analysis of its contribution to urban governance and the millennium development goals. Quito: Working Paper, 2004.

UTZIG, J. E. ; GuimARAENS, R. Democracia e participação popular na esfera pública: a experiência de Porto Alegre. In: BonduKI, N. (org.). Habitat: as práticas bem-sucedidas em habitação, meio ambiente e gestão urbana nas cidades brasileiras. São Paulo: Studio Nobel, 1996.

WAMPleR, B. "A difusão do Orçamento Participativo brasileiro: 'boas práticas' devem ser promovidas?". Opinião Pública, vol. 14, n 1, p. 65-95, 2008.

WeYLAND, K. Bounded rationality and policy diffusion. Nova Jersey: Princeton University Press, 2006.

WORLD BANK. Entering the 21st Century: world development report, 1999/2000. Oxford: Oxford University Press, 2000.

Municipal development in Mozambique: lessons from the first decade. Vol 1: Synthesis Report. Washington: World Bank, 2009. 


\section{Resumo}

Mecanismos da difusão global do Orçamento Participativo: indução internacional, construção social e circulação de indivíduos

Este artigo trata da difusão global do Orçamento Participativo (OP) brasileiro. Desenvolvido em Porto Alegre no final dos anos 1980, essa política de participação social foi adotada, nos dias atuais, por cerca de 2.800 governos. Procura-se responder às seguintes perguntas: como o OP passou de uma experiência local para uma referência global? Que mecanismos facilitaram esse movimento? $E_{\text {, por }}$ fim, de que maneira essa política de participação social se transformou ao longo do processo de difusão internacional? A partir de uma extensa "etnografia política transnacional", foram identificados três mecanismos operando na difusão do OP: a indução institucional, a construção social e a circulação internacional de indivíduos. O argumento é que um grupo de indivíduos, os "embaixadores da participação", foi fundamental para inserir o OP na agenda das instituições internacionais. Uma vez que o OP se insere na agenda das instituições internacionais, seu potencial de difusão é ampliado. O reconhecimento do OP pelas organizações internacionais mostra a importância que esse tema vem adquirindo em escala global. Todavia, a observação empírica revela que, a despeito da vasta difusão do OP, os significados que são atribuídos por cada um dos atores a essa política são muito distintos.

Palavras-chave: difusão de políticas públicas; orçamento participativo; organizações internacionais; Fórum Social Mundial; Banco Mundial

\section{Abstract}

Global diffusion mechanisms of the Participatory Budgeting program: international induction, social construction, and circulation of individuals.

This article deals with the global diffusion of Participatory Budgeting (PB). Developed in Porto Alegre at the end of the 1980s, this social participation policy has been adopted by about 2,800 governments. The aim of this work is to answer the following questions: Why did PB move from a local policy to a global one? What mechanisms facilitated this movement? Lastly, in what ways was this policy transformed along the process of international diffusion? Relying on an extensive transnational political ethnography, this study found that three mechanisms were operating along the massive diffusion of PB: institutional induction, social construction, and the international circulation of individuals. The argument is that a group of individuals-the "ambassadors of participation"-was fundamental to introducing PB to the agenda of international institutions. The moment that PB was set on the agenda of international institutions its diffusion potential was amplified. The recognition of PB by international organizations reveals the importance that this issue is gaining on a global scale. Although, empirical observation shows that, in spite of the vast diffusion of $\mathrm{PB}$, the meanings given to this policy can be very different according to the actor.

Keywords: Policy Diffusion; Participatory Budgeting; International Organizations; World Social Forum; World Bank

\section{Resumen}

Mecanismos de difusión global del presupuesto participativo: inducción internacional, construcción social y el movimiento de las personas

Este artículo trata de la difusión global de Presupuesto Participativo (PP) desde Brasil. Desarrollada en Porto Alegre a finales de 1980 , hoy en día esta política de participación social fue adoptada por cerca de2800 gobiernos. Se pretende responder a las siguientes preguntas: ¿Cómo el PP pasó de una experiencia local a una referencia global?, ¿Cuáles mecanismos han facilitado este movimiento? y, por último, ¿Cómo esta política de participación social se ha transformado durante el proceso de difusión internacional? A partir de una extensa "etnografía política transnacional" fueron identificados tres mecanismos que operan en la difusión del PP: inducción institucional, la construcción social y la circulación internacional de personas. El argumento es que un grupo de 
individuos, llamados "embajadores de la participación" fue clave para que el PP entrara en la agenda de las instituciones internacionales. Desde que el PP se incluye en la agenda de las instituciones internacionales su potencial de propagación se expande. El reconocimiento del PP por los miembros de las organizaciones internacionales muestra la importancia que esta cuestión ha adquirido a una escala global. Sin embargo, la observación empírica muestra que, a pesar de la amplia difusión del $\mathrm{PP}$, los significados que son asignados por cada uno de los actores en esta política son muy diferentes.

Palabras clave: difusión de políticas públicas; Presupuesto Participativo; Organizaciones internacionales; Foro Social Mundial; Banco Mundial

\section{Résumé}

Mécanismes de diffusion globale du Budget Participatif: induction internationale, construction sociale et circulation d'individus

Cet article traite de la diffusion globale du Budget participatif (BP) brésilien. Développé à Porto Alegre à la fin des années 1980, aujourd'hui cette politique de participation sociale a été adoptée par environ 2800 gouvernements. Cet article cherche à répondre aux questions suivantes: comment le BP est passé d'une expérience locale à une référence globale, quels mécanismes ont facilité ce mouvement et, enfin, comment cette politique de participation sociale s'est-elle transformée au cours du processus de diffusion internationale? A partir d'une vaste "ethnographie politique transnationale", un ensemble de trois mécanismes opérant dans la diffusion du BP a été identifié: l'induction institutionnelle, la construction sociale et la circulation des individus. L'argument qui en ressort est qu'un groupe d'individus, les "ambassadeurs de la participation", a été crucial pour que le $\mathrm{BP}$ se retrouve à l'ordre du jour dans les institutions internationales. Depuis que le BP a été inclus à l'ordre du jour des institutions internationales, le potentiel de sa propagation s'est élevé. La reconnaissance du BP par les organisations internationales montre l'importance que cette question a acquise à une échelle mondiale. Cependant, l'observation empirique révèle que, en dépit de sa large diffusion, les significations attribuées par chaque acteur à cette politique publique sont très différentes.

Mots-clés: diffusion des politiques publiques; Budget Participatif; organisations internationales; Forum Social Mondial; Banque Mondiale

Artigo submetido à publicação em setembro de 2015. Versão final aprovada em julho de 2016. 